\title{
Mathematical Logic Establishment for Automated Trash Controlling in Carding Machine
}

\author{
Md. Redwanul Islam, Lecturer, \\ Department of Textile Engineering, Primeasia University \\ Numan Zubaer, Production Officer, \\ Matin Spinning Mills.Ltd (DBL group) \\ Tareq Iqbal, Lecturer, \\ Md. Abir Khan, Lecturer, \\ Department of Textile Engineering, Primeasia University
}

Doi: 10.19044/esj.2019.v15n3p38～URL:http://dx.doi.org/10.19044/esj.2019.v15n3p38

\begin{abstract}
In this paper, it is intended to establish a mathematical logic for the purpose of removal of trash in an automatic way and removal of trash will refer to the cleaning process of carding machine. But the selection of degree of cleaning has to be optimum considering other process factors like fiber loss, fiber rupturing, neps generation etc. Higher degree of cleaning causes higher degree of fiber loss. And in spinning mill, fiber loss means money loss as raw cotton purchasing cost consumes $50 \%$ to $60 \%$ of total manufacturing cost of yarn in terms of Bangladesh. Alongside, fiber loss is affected the cleaning system because the system is designed for fiber cleaning, not for fiber loss. So, it is necessary to measure the performance of the system. For this purpose, we have chosen two terms, 'Cleaning Efficiency (C.E.)' to measure the degree of cleaning \& 'Effective Cleaning (E.C.)' to measure the performance of the system. In this paper, it is intended to describe a relationship between these two terms, graphical expression of the individuals, a way to calculate the force applied by mechanical means and the force required to clean. The ultimate result of this project is to find the relationship between the surface speed of taker-in and the trash weight of output material.
\end{abstract}

Keywords: Cleaning Index, Cleaning Efficiency, Effective Cleaning and Trash content

\section{Introduction}

Fiber cleaning is a very common and obviously a mandatory action, in fact done only at two stages, i.e., blow room line \& carding machine throughout the whole process in spinning mill as raw cotton contains dust, 
trash and some other foreign matters. This paper will deal only with the carding machine to remove the trash.

\section{Function of Taker-in Region of Carding}

Among the various operating regions in carding machine, only the taker-in region will be discussed and among only the elimination of impurities like trash will be considered throughout this paper.In the case of a revolvingflats carding machine the theory predicts a "strong" aerodynamic mechanism between taker-in and cylinder and a "weak" mechanism between cylinder and removal cylinder resulting in effective transfer in the first case and a more limited transfer in the second.(LEE\&OCKENDON,2006).

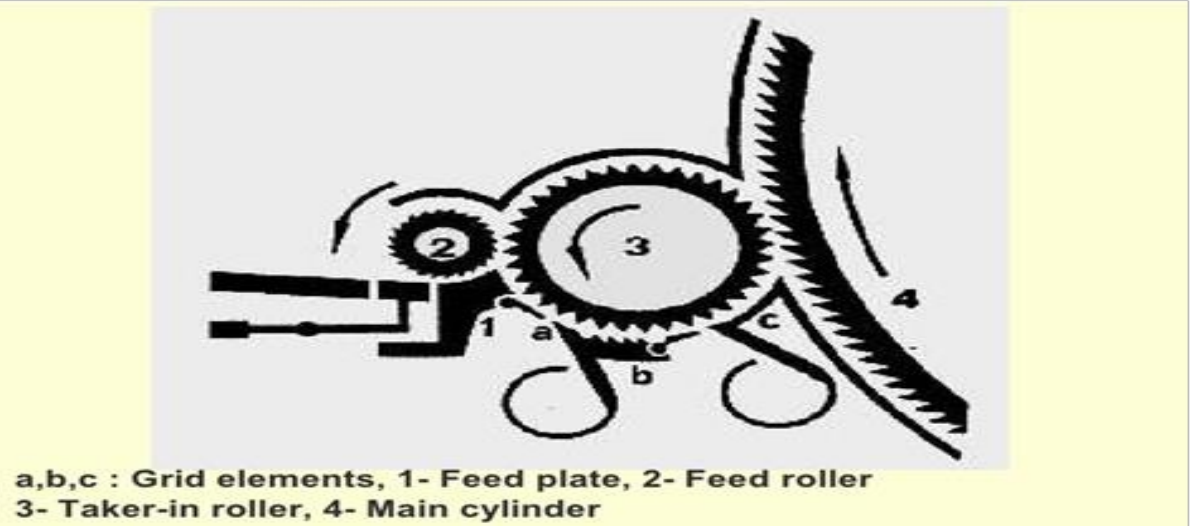

Figure 1.Trash Removal Function of Taker-in Region

Chute feed system supplies raw material by ducting pipe of evenly compressed a bat of 500-900 ktex . Feed arrangement consisting of feed plate (1) and feed roller (2) that transfers the material to the taker-in (3) roller. Taker-in opens the material in small tufts. The high peripheral speed of the taker-in results in all particles heavier than fibers(trash and other extraneous particles) being removed outward at this opening while the fibers continue with the roller, to be passed over grid equipment and later into the cylinder. In moving past, mote knives, grids, carding segments etc, the material loses majority of its impurities and the suction ducts carry away the waste.

\section{Cleaning Index}

It is found in the book „Manual of Textile Technology (Volume1) wrote by (W.Klein,1987). The writer introduces the term to measure the degree of cleaning and RIETER also takes the concept for practical use. Accordingly the cleaning index is given by

$$
\text { Cleaning Index, CT }=\frac{D F-D D}{D F} * 100 \%
$$


Where, DF $=$ Dirt content of the feed material

DD $=$ Dirt content of the delivery material

$\mathrm{T} \quad=$ Total

W. Klein says, "The cleaning index is strongly, but not solely, dependent on the dirt content. The particle size and adhesion of the dirt to the fibers, among other things, also have an influence. Hence, the cleaning index may be different for different cotton types with the same dirt content." W Klein also makes a graph of degree of cleaning in different machines of blow room and carding machine.

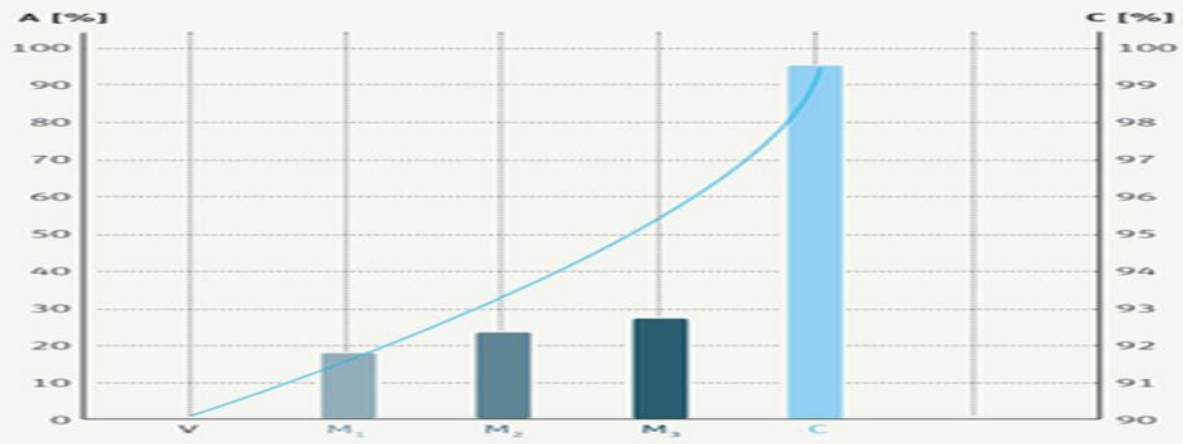

Figure 2. Increasing degree of cleaning from machine to machine

Here, $\mathrm{A}=$ Degree of Cleaning of Blow room Machines, $\mathrm{C}=$ Degree of Cleaning of V (Feed Material), M1 - M3 (Machines 1-3), C (Carding Machine). From the graph, we can see that the degree of cleaning of carding machine is maximum and the range is $90 \%$ to over $99 \%$. But the degree of cleaning of blow room machineries is comparatively low and the range is $18 \%$ to below $30 \%$. It must be noted down that the degree of cleaning of different machineries are affected by the types of raw material used.

\section{Cleaning Efficiency(CE)}

It has been reported that the quantity of waste eliminated on a cleaning machine by modifying settings, speeds was raised from $0.6 \%$ to $1.2 \%$ while the quantity of the foreign matter eliminated increased by only $41 \%$, the quantity of fibers eliminated increased by $240 \%$. Normally, fibers represent about $40 \%$ to $60 \%$ of blow room waste. Thus, in order to clean, it is necessary to eliminate about as much fibers as foreign material. Since the proportion of fibers in waste differs from one machine to another, and can be strongly influenced, the fiber loss at each machine should be known. It can be expressed as a percentage of good fiber loss in relation to total material eliminated, i.e. in cleaning efficiency (CE) 
Where, $\quad$ AT $=$ Total waste\%

$$
\mathrm{CE}=\frac{A T-A F}{A T} * 100 \quad(\text { Frydrych1\&Matusiak,2002) }
$$

$\mathrm{AF}=$ Good fibers eliminated $\%$

Trutzschler established a graph to analyze the effect on process like degree of cleaning, fiber loss, and neps generation keeping the feed material trash $\%$ as variable for corresponding degree of cleaning.

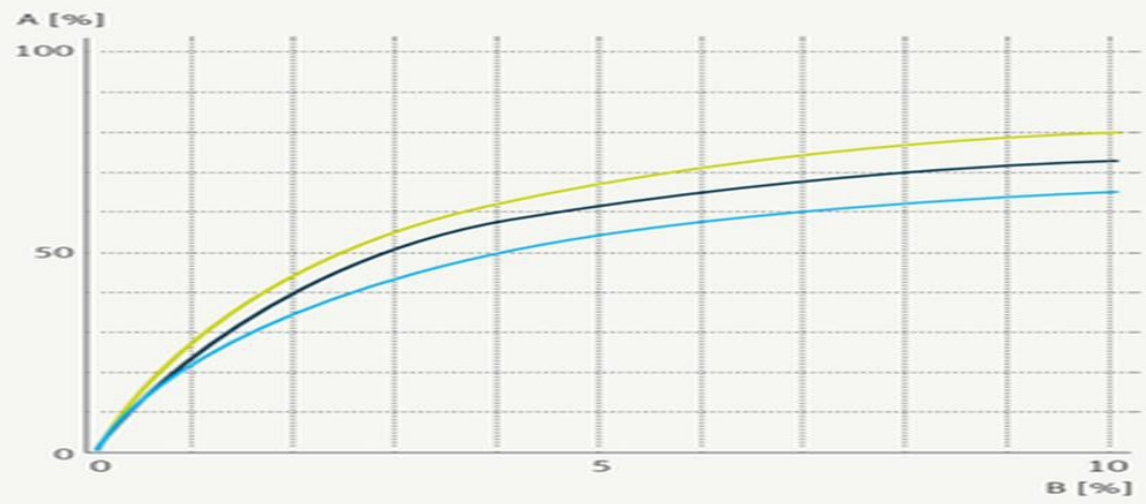

Figure 3. Degree of cleaning (A) as a function of trash content (B) of the raw material.

Here, Yellow Line $=$ Degree of Cleaning

Deep Blue Line $=$ Fiber Loss

Light Blue Line $=$ Neps Generation .

Fiber loss and neps generation are inter connected with the degree of cleaning. If we increase the degree of cleaning, fiber loss as well as neps generation will be increased (Chaouch et al (2006).

\section{Effective Cleaning}

Carl.A.Lawrance (2003) mentions some unavoidable fiber loss occurs during mechanical cleaning. The settings of grid spacing will evidently control the fiber content of the waste. When considering the fiber loss, the effective cleaning (EC) of a machine can be defined as

$$
\text { Effective Cleaning, } \mathrm{EC}=\frac{W T-W F}{W I N} * 100
$$

Where, WT = Mass of waste

$\mathrm{WF}=$ Mass of fiber in the waste

WIN = Mass value of impurities in the fiber at the input"

Lawrance also defined about a concept of cleaning efficiency as 


$$
\text { Cleaning Efficiency, } \mathrm{CE}=\frac{\text { WIN-WOUT }}{\text { WIN }} * 100
$$

Where, WIN = Mass value of impurities in the fiber at the input WOUT $=$ Mass value of impurities in the fiber at the output

RIETER \& Trutzschler worked with the trash removal concept by keeping the input material trash\% as a variable. That leads to different experiments to find the optimum level of input material trash\% but how to maintain the constant optimum level of output material trash\% against a particular input material trash\% is not discussed.

Though the companies are working with different terms, both of them are working for maintain standard quality.

\section{Materials \& Methods}

The concept has grown up from three different terms collected from three different sources. Terms are interconnected and a mathematical logic can be established to get an optimum level of removal of trash. So, the key terms are: cleaning Index, cleaning Efficiency and Effective cleaning.

\section{Deduction of Relationship between CE \& EC}

By the definition of cleaning Efficiency,

$$
\begin{aligned}
& \mathrm{CE} \%=\frac{\text { TIN-TOUT }}{T I N} * 100 \% \\
& \mathrm{OR}, \quad \mathrm{CE} \%=\frac{T R}{T I N} * 100 \%
\end{aligned}
$$

Where, TIN = Trash weight of input material

TOUT $=$ Trash weight of output material

$\mathrm{TR}=$ Removed trash weight

By the definition of effective cleaning,

$\mathrm{EC} \%=\frac{T R-F T}{T I N} * 100 \%$

Where, $\mathrm{FT}=$ Fiber mass in removed trash

$$
\begin{array}{ll}
\text { Or, } & \mathrm{EC} \%=\frac{T R}{T I N} * 100 \%-\frac{F T}{T I N} * 100 \% \\
\text { Or, } & \mathrm{EC} \%=\mathrm{CE} \%-\frac{F T}{T I N} * 100 \% \quad ;[\text { From equation (2)] }
\end{array}
$$

Therefore, $\mathrm{EC} \%=\left(\mathrm{CE}-\frac{F T}{T I N}\right) * 100 \%$

This is the relationship between cleaning efficiency \& effective cleaning. 


\section{Graphical Expression of CE}

From equation (1),

$$
\mathrm{CE} \%=\frac{T I N-T O U T}{T I N} * 100 \%
$$

Taking trash weight of input material as constant and hence, the cleaning efficiency will depend on the trash weight of output material. So, a function can be defined in terms of trash weight of output material.

$$
\text { Say, } \mathrm{TIN}=\mathrm{a}, \mathrm{TOUT}=\mathrm{x} \& \mathrm{f}(\mathrm{x})=\mathrm{y}
$$

Then the equation (1) can be written as, $\mathrm{f}(\mathrm{x}) \%=\frac{a-x}{a}$

Or, $\mathrm{f}(\mathrm{x}) \%=1-\frac{x}{a}$

Or, $\mathrm{y} \%+\frac{x}{a}=1$

Or, $\frac{y}{100}+\frac{x}{a}=1$

Therefore, $\frac{x}{a}+\frac{y}{100}=1$

But, this is an equation of straight line cutting from both $\mathrm{x}$ axis and $\mathrm{y}$ axis respectively at $(\mathrm{a}, 0)$ and $(0,100)$ points. Here, the $\mathrm{x}$ axis represents the trash weight of output material and the $\mathrm{y}$ axis represents the cleaning efficiency \%. If a point $\mathrm{A}$ is considered on the straight line, the coordinate indicates the corresponding efficiency against a particular trash mass of output material. So, the points on the straight line satisfy the equation (5) as well as the equation (1) and indicate that the process is efficient. Efficient process means that the mechanical force and the actual cleaning force are same. However, the set of points satisfying the equation (1) is $\mathrm{SCE}=\{\mathrm{x}: \mathrm{x} \in \mathbb{N}$ and $\mathrm{f}(\mathrm{x}) \%=1-\mathrm{x} / \mathrm{a}\}$.

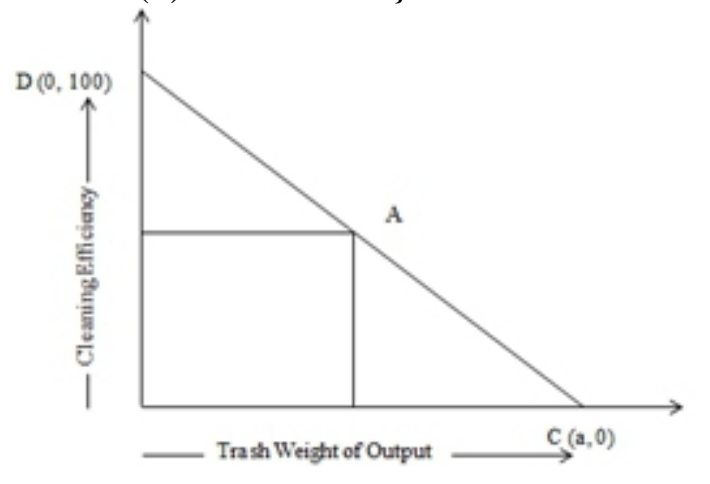

Figure 4. CE Vs Trash weight of output. 


\section{Graphical Expression of EC}

From equation (4), $\quad \mathrm{EC} \%=\left(\mathrm{CE}-\frac{F T}{T I N}\right) * 100 \%$

Let, trash weight of input material and the cleaning efficiency are constant and hence the effective cleaning will depend on the fiber weight in removed trash. So, a function can be defined in terms of fiber weight in removed trash.

$$
\text { Say, } \mathrm{TIN}=\mathrm{a}, \mathrm{CE}=\mathrm{b}, \mathrm{FT}=\mathrm{x} \quad \& \mathrm{f}(\mathrm{x})=\mathrm{y}
$$

Then the equation (4) will be, $\mathrm{f}(\mathrm{x}) \%=\mathrm{b}-\frac{x}{a}$

Or, $\mathrm{y} \%+\frac{x}{a}=\mathrm{b}$

Or, $\frac{y}{100}+\frac{a}{a}=b$

Or, $\frac{y}{100 b}+\frac{x}{a b}=1$

Therefore, $\frac{x}{a b}+\frac{y}{100 b}=1$

But, this is also an equation of straight line cutting from both $\mathrm{x}$ axis and $y$ axis respectively at $(a b, 0)$ and $\left(0, b^{*} 100\right)$ points.

Here, the $\mathrm{x}$ axis represents the fiber weight in trash and the $\mathrm{y}$ axis represents the Effective Cleaning percentage. If a point $B$ is considered on the straight line, the coordinate indicates the corresponding effectiveness against a particular fiber weight in trash. So, the points on the straight line satisfy the equation (6) as well as the equation (4) and indicate that the process is effective.

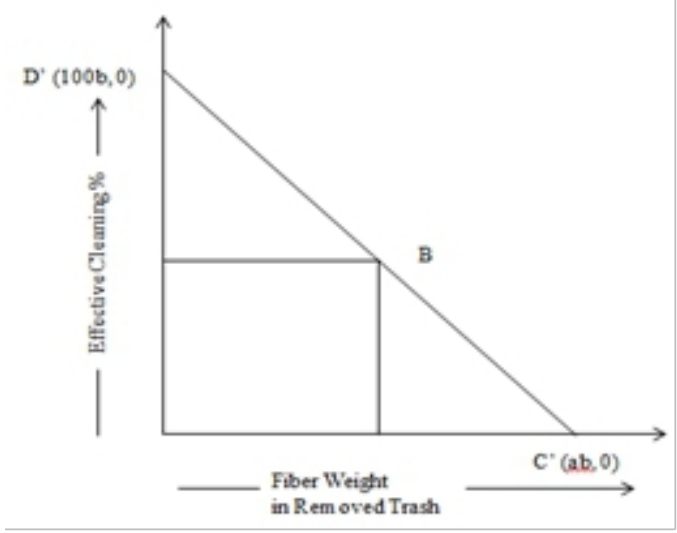

Figure 5. EC Vs Fiber weight in removed trash.

However, the set of points satisfying the equation (4) is, Set of $E C=\{x: x \varepsilon$ $\mathbb{N}$ and $\mathrm{f}(\mathrm{x}) \%=\mathrm{b}-\mathrm{x} / \mathrm{a}\}$. 


\section{Cleaning Force Calculation}

From figure 4 we can calculate a relationship between required cleaning force and the applied mechanical force. For the efficient process, both of them will be equal. If the forces are not equal, the process is not efficient. From the graphical expression of CE,

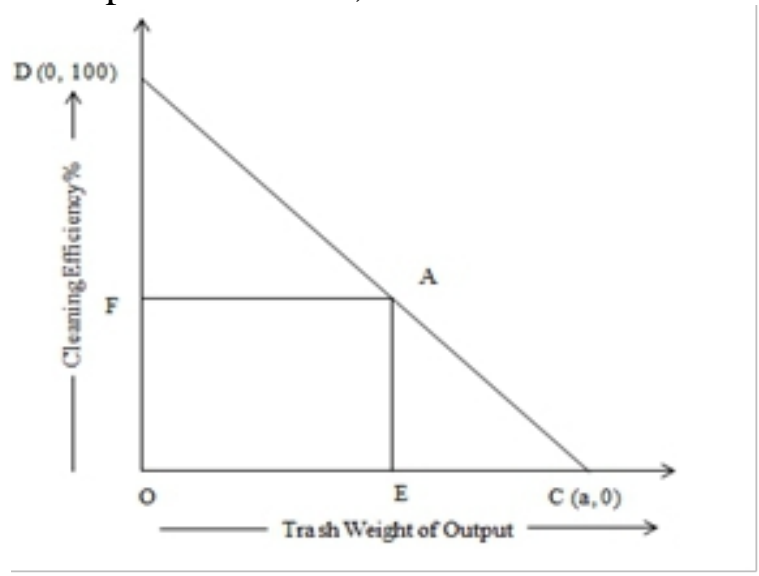

Figure 6. CE Vs Fiber weight in removed trash.

AFD \& AEC are equiangular triangle. So, $\frac{F D}{E A}=\frac{F A}{E C}$

$\mathrm{Or}, \mathrm{FD} * \mathrm{EC}=\mathrm{FA} * \mathrm{EA}$

$\mathrm{Or}, \mathrm{FD}^{*} \mathrm{EC}=\mathrm{OE} * \mathrm{OF}$

Therefore, $\mathrm{OE} * \mathrm{OF}=\mathrm{FD} * \mathrm{EC}$

So, for an efficient process, product of trash weight of output material and cleaning efficiency will be equal to the product of removed trash weight and the complement of cleaning efficiency. As the product of trash weight of output material and cleaning efficiency Percentage expresses a weight and the weight is one kind of force, we are addressing it as Cleaning Force. On the other hand, product of removed trash weight and the complement of cleaning efficiency Percentage also express a weight and we are addressing it as Mechanical Force.

From equation (7), we get,

Trash weight of Output Material * Cleaning Efficiency $\%=$ Removed Trash Weight * Complement of Cleaning Efficiency\%

Here, in this project, we will consider only the rotational speed of taker-in to generate the mechanical force.

So, Mechanical Force, M.F. $=\frac{m V^{2}}{D / 2} \&$ Cleaning Force, C.F. $=\mathrm{x} *$ C.E\% Where, $\mathrm{m}=$ Mass of Taker-in 
Where, $\mathrm{x}=$ Trash Weight of Output Material

$\mathrm{V}=$ Linear Velocity of Taker-in

C.E\% = Cleaning Efficiency \%

$\mathrm{D}=$ Diameter of the Taker-in

For efficient process,

Cleaning Force $=$ Mechanical Force $\mathrm{x} * \mathrm{C} . \mathrm{E} \%=\frac{m V^{2}}{D / 2}$

$$
\text { Or, } \mathrm{x}=\frac{2 m}{C \cdot E \% * D} V^{2}
$$

For a constant cleaning efficiency and a fixed taker-in $\frac{2 m}{C . E . \% * D}$ will be a constant.

$$
\text { So, } \mathrm{x}=\mathrm{k} * \mathrm{~V}^{2} \quad ; \text { where, } \mathrm{k}=\frac{2 m}{\text { C.E. } \% * D}
$$

Therefore, $\mathrm{x} \alpha \mathrm{V}^{2}$ From the above derivation we can say that square value of the velocity of the taker-in is directly proportional to the trash weight of output material.

\section{Result \& Discussion}

This project is grown up on the basis of a theoretical concept and at present it is not practically used. So, this paper cannot afford a real life practiced data. But it will provide some virtual data on the basis of some virtual command developed in the $\mathrm{C}$ program.

\section{Limitation of this work}

The aim of this work is to establish a mathematical logic. Besides, the project has some other limitations like:

- Only the surface speed of taker-in is accounted for this project.

- But there are some other parameters like grid setting, mote knives etc. are not taken into account.

\section{Conclusion}

Actually, it is a theoretical concept to remove trash automatically from the feed material in the carding machine with the aid of some logic established here which are mathematically proved. The graph of cleaning efficiency versus trash weight of output material shows a straight line. For an efficient process all the points have to lie on this line. The graph of effective cleaning versus fiber weight in removed trash shows also a straight line. But this is impossible to have all the points lying on this line because it is natural to loose fibers in the process of removal of trash. It can be minimized in an optimum level. For this purpose, help can be taken from matrix data analysis to build up a classimat matrix like used in winding machine. 


\section{References:}

1. W. Klein. (1987). The Technology of Short-staple Spinning, Volume 1, The Textile Institute, Manchester

2. Walid Chaouch, Mohamaed Ben Hassaen, Sakli Faouzi ,(1/2006), Melliand International

3. M.E.M. LEE1,* and H. OCKENDON, Springer 2006, Journal of Engineering Mathematics (2006)

4. I. Frydrych, M. Matusiak,(2002), FIBRES \&TEXTILES in Eastern Europe

5. Carl A. Lawrance,(2003), Fundamentals of Spun Yarn Technology, Article 2.2.5.3 